\title{
PERANCANGAN SIGN SYSTEM KAMPUNG MADRAS KOTA MEDAN
}

\author{
Muhammad Sabri \\ Prodi Desain Komunikasi Visual \\ Fakultas Seni dan Desain Universitas Potensi Utama Medan \\ shabry92@gmail.com
}

\begin{abstract}
ABSTRAK
Kampung Madras merupakan salah satu daerah yang unik dan khas serta menyimpan berbagai macam sejarah didalamnya, salah satunya bangunan bersejarah Kuil Shri Mariamman sebagai bukti ada dan berkembangnya etnis Tamil dikota Medan. Dari awal terbentuknya, daerah tersebut lebih dikenal dan populer dengan sebutan Kampung Keling. Kampung Madras merupakan pemukiman yang mayoritas dihuni oleh etnis Tamil. Kurangnya sarana petunjuk (signage) di Kampung Madras, seringkali membuat para wisatawan yang ingin berkeliling di kampung Madras kebingungan sehingga menyebabkan aktivitas para pengunjung terganggu. Disini saya membuat alternatif solusi sebagai salah satu cara untuk menyelesaikan permasalahan tersebut yaitu dengan membuat sign system terkonsep sehingga lebih menarik wisatawan untuk melihatnya. Konsep ide perancangan sign sytem diambil dari bentuk Kuil Shri Mariamman yang menjadi icon kampung Madras tersebut.
\end{abstract}

Kata Kunci : Kampung Madras, Kota Medan, Kuil Shri Mariamman, Sign System.

\section{ABSTRACT}

Kampung Madras become one of the interesting village and save a lot of history in it, one of which is the historic building of Shri Mariamman Temple as a proof of the existence of Tamil ethnic in Medan city. Since its inception, this village area is popular and better known as Kampung Keling. Kampung Madras is a predominantly settled settlement of ethnic Tamil. The lack of signage facilities in Kampung Madras, often making tourists who want to get around in Madras confuse, causing disturbed visitor activity. Here I made an alternative solution as one way to solve this problem, namely by creating a conceptual sign system so that it is more attractive for tourists to see it.. The concept of sign sytem design is derived from Shri Mariamman Temple which became the icon of Kampung Madras.

Keywords : Kampung Madras, Medan City, Shri Mariamman Temple, Sign System.

\section{PENDAHULUAN}

Kurangnya sarana petunjuk (signage) di Kampung Madras, seringkali membuat para wisatawan yang ingin berkeliling di kampung Madras kebingungan sehingga menyebabkan aktivitas para pengunjung terganggu. Disini saya membuat alternatif solusi sebagai salah satu cara untuk menyelesaikan permasalahan tersebut yaitu dengan membuat sign system terkonsep sehingga lebih menarik wisatawan untuk melihatnya. Konsep ide 
perancangan sign sytem diambil dari bentuk kuil shri mariamman yang menjadi icon kampung Madras tersebut.

Kampung Madras merupakan sebuah daerah yang pada mulanya ditempati oleh mayoritas masyarakat etnis Tamil. Mereka pada awalnya datang ke kota Medan untuk bekerja di industri perkebunan tembakau Deli sebagai pekerja perkebunan, selain dari pada itu etnis Tamil merupakan pembawa ajaran agama Hindu dan Buddha, seperti yang kita ketahui masyarakat etnis Tamil ini sangat pandai dalam mengolah rempah-rempah makanan dan keahlian mereka itu pun terbawa ketika mereka masuk ke kota Medan. dahulunya penyebutan nama daerah ini adalah Kampung Keling yang memiliki arti kampung hitam, karena penyebutan keling terkesan negatif, pada tahun 2008 dilakukan pergantian nama menjadi Kampung Madras. (Siska, 2016)

Daerah ini memiliki memiliki daya tarik wisatawan karena memiliki beberapa objek wisata dengan berbagai keunikan dan sejarah yang sangat tua. Salah satunya yang menjadi bangunan yang paling bersejarah dan khas di tempat ini adalah kuil Shri Mariamman yang didirikan pada tahun 1884 dan juga Mesjid Ghaudiyah yang didirikan tahun 1887. Kedua bangunan tempat ibadah tersebut didirikan oleh masyarakat etnis Tamil yang mendiami tempat tersebut. Kuil tersebut dibangun oleh etnis Tamil yang beragama hindu dan budha, begitu pula dengan masjid yang ada di tempat tersebut yang didirikan oleh etnis Tamil namun yang beragama islam. Masih banyak beberapa objek wisata yang ada di kampung Madras ini seperti tempat penjualan makanan dan pakaian khas pakistan dan india, gereja kristen Indonesia dan Vihara Gunung Timur yang juga memiliki sejarah yang cukup tua, pedagang petasan, pasar, swalayan serta mall Sun Plaza dan masih banyak juga yang lainnya.

\section{STUDI LITERATUR}

Sign system merupakan media yang digunakan untuk melakukan interaksi antar manusia di ruang publik. Pada penelitian kali ini ruang publik yang dimaksud adalah Kota Madras, dan dapat dipastikan banyak sekali pengunjung yang membutuhkan media sebagai petunjuk arah ketika berada di lingkungan tersebut. Berdasarkan buku The Wayfinding Handbook yang disusun oleh David Gibson (2009: 49), sign system terbagi menjadi beberapa jenis: 


\section{a. Tanda Identifikasi (Identification)}

Tanda identifikasi seringkali menjadi petunjuk deskripsi pertama dari sebuah tempat tujuan. Tanda tersebut merupakan penanda visual yang menunjukkan nama dan fungsi dari sebuah tempat atau ruang. Papan penanda identifikasi ini digunakan unruk menjelaskan atau mendeskripsikan suatu objek, seperti identitas gedung, kantor, bangunan atau perusahaan. Penanda pada kampung Madras untuk memberikan identitas untuk membedakan suatu objek, karena di kampung Madras ada beberapa objek yang perlu diketahui masyarakat.

\section{b. Tanda Direksional (Direction)}

Tanda direksional mengatur sistem sirkulasi dari sebuah program penunjuk arah karena mereka memberikan petunjuk yang dibutuhkan sehingga pengguna dapat terus bergerak setelah mereka memasuki sebuah ruang. Tanda direksional ini menggunakan bantuan visual seperti tipografi, simbol, dan panah. Penanda ini pada wilayah kampung Madras sama sekali belum ada, maka dari itu perlu dibuatkannya tanda ini agar memudahkan pada wisatawan dalam berkeliling di wilayah kampung Madras.

\section{c. Tanda Orientasi}

Tanda orientasi ini menyuguhkan pada pengunjung sebuah gambaran luas dari lingkungan di sekeliling mereka dalam bentuk peta lokasi komprehensif dan arahan. Didalam desain Tanda ini terdapat informasi beberapa objek sasaran dan petunjuk arah untuk menuju ke lokasi objek tersebut. Tanda orientasi ini biasanya berupa unit berdiri berukuran besar yang dapat dilihat oleh banyak orang sekaligus, atau ditempel di dinding jika ruang yang ada tidak cukup. Tanda ini nantinya akan menunjukkan peta objek-objek wisata yang ada di kampung Madras dan di letakkan di tempat yang strategis agar para wisatawan dapat dengan mudah melihat denah lokasi objek-objek wisata lainnya yang ada di kampung Madras.

d. Tanda peringatan (Regulation) atau larangan

Tanda ini bertujuan untuk mendeskripsikan mengenai sesuatu yang diperbolehkan dan tidak boleh dikerjakan atau juga dilarang. Selain dari pada itu, tanda ini juga menginformasikan supaya audiens lebih berhati-hati. Dalam penyajian sign system, dibutuhkan beberapa strategi visual agar dalam penyampaian pesan dapat dengan 
mudah ditangkap oleh pengunjung. Pada dasarnya sign system merupakan kumpulan dari beberapa tanda individual yang sudah dibuat desainnya dengan tujuan mengarahkan lalu lintas atau sebagai suatu penjelas deskripsi suatu bangunan. Tanda ini di setiap wilayah pasti sudah ada, namun hanya memiliki desain yang standart, namun pada kali ini penulis akan memberikan alternatif desain dengan konsep khas kampung Madras agar lebih menarik wisatawan untuk melihatnya.

\section{PEMBAHASAN}

Perancangan ini nantinya setelah pengumpulan data selesai selasai, maka akan di lakukan pengamatan pada desain pengembangan suatu wilayah. Perancangan di mulai dengan brainstorming kemudian di spesifikasikan data tersebut menggunakan metode Mind Mapping. Dengan menggunakan pengolahan data tersebut, maka akan menghasilkan beberapa bayangan visual berupa foto, layout, ilustrasi dan warna.

Perancangan sign system ini setelah data di lengkapi, kemudian dilanjutkan dengan sketsa dasar dengan beberapa alternatif di dalamnya, lalu di seleksi kemudian di lanjutkan dengan menggunakan software grafis, sampai pada akhirnya tercipta final desain yang di aplikasikan ke dalam media utama maupun media pendukung.

Konsep kreatif merupakan sebuah tema, ide pokok atau gagasan unik yang akan diangkat dan dikemas menjadi sebuah produk komunikasi visual. Secara garis besar konsep kreatif merupakan titik awal yang sangat penting untuk menemukan berbagai gagasan baru dan belum pernah ada sebelumnya, agar apa yang akan dikomunikasikan mempunyai sebuah karakteristik atau pembeda. Untuk perancangan desain ini, ada beberapa ide pokok yang akan dijadikan sebagai pijakan dalam perancangannya. Ide tersebut adalah sebagi berikut:

1. Kuil Shri Mariamman 


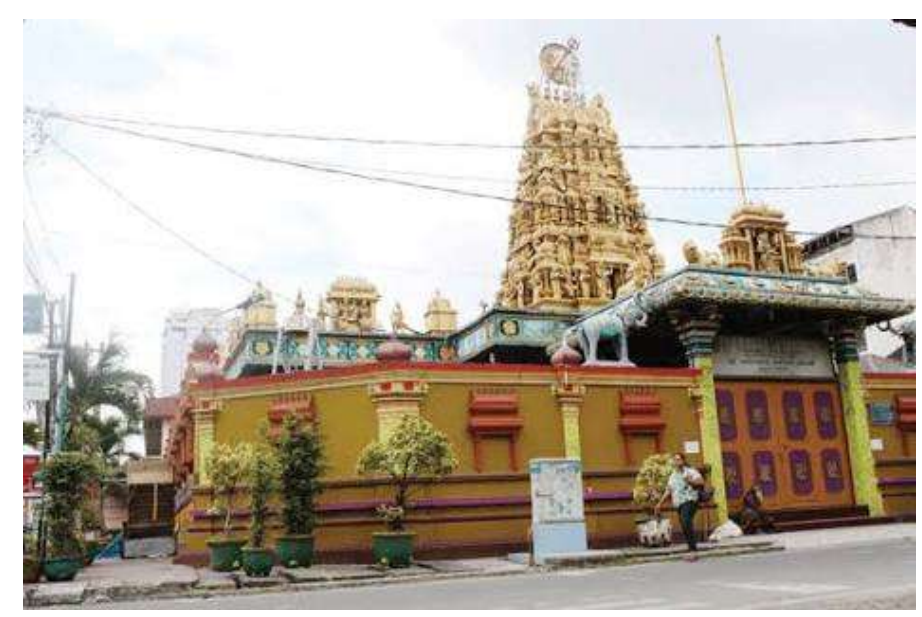

Gambar 1. Kuil Shri Mariamman (Sumber:Dokumentasi Pribadi, 2016)

2. Kebudayaan dan kuliner khas india

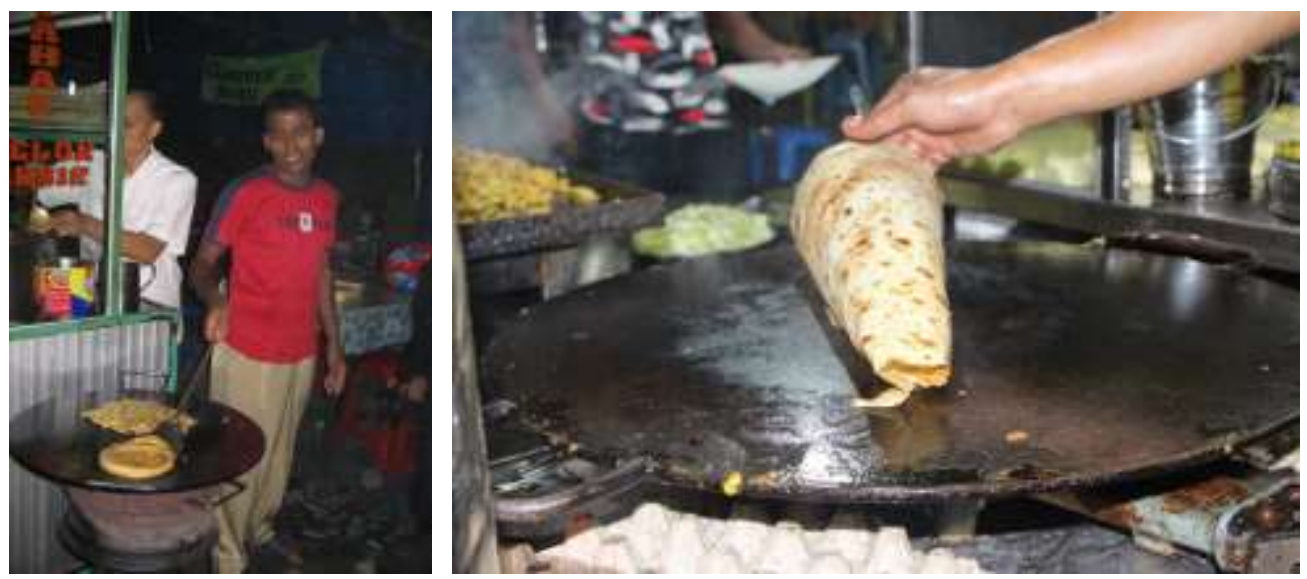

Gambar 2. Kuliner Khas Kampung Madras

(Sumber:Dokumentasi Pribadi, 2016)

3. Masjid Ghaudiyah

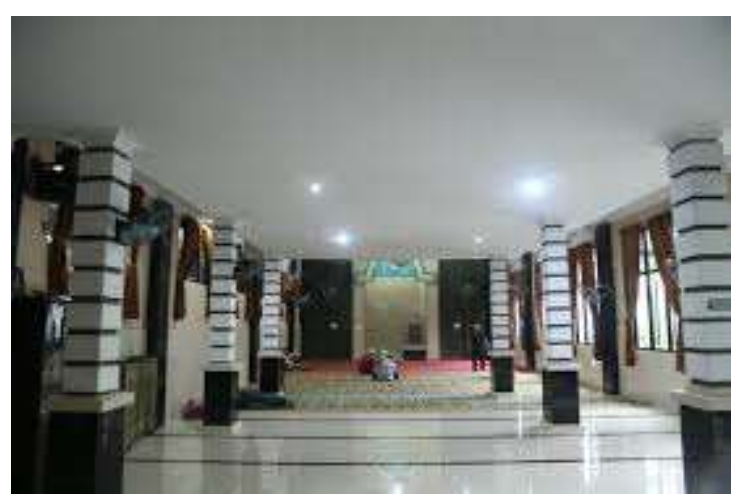

Gambar 3. Masjid Ghaudiyah

(Sumber:Dokumentasi Pribadi, 2016)

4. Vihara Gunung Timur 


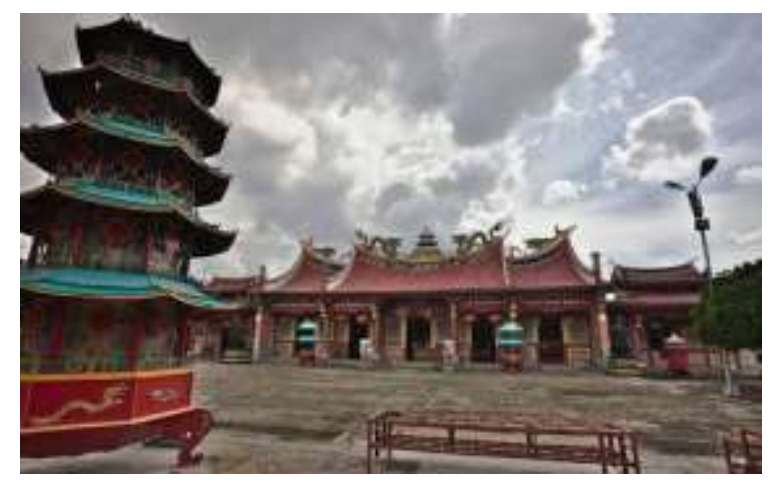

Gambar 4. Vihara Gunung Timur

(Sumber: Dokumentasi Pribadi, 2016)

Beberapa ide besar di atas dapat diwujudkan ke dalam bentuk visual yang menarik agar bisa menarik perhatian target audience, dan diaplikasikan ke dalam beberapa desain, seperti sign system, desain maskot, landmark, dan desain penunjang wisata kuliner.

\section{I.1. STRATEGI MEDIA}

Strategi media merupakan suatu metode yang diterapkan untuk mencapai tujuan media. Strategi media kita mengenal istilah paduan media, yang berarti sebuah pertimbangan pemilihan media yang akan diaplikasikan dalam kegiatan publikasi.

Perancangan pengembangan wilayah kampung Madras ini, media utama yang akan digunakan adalah Sign System. Media ini dirasa sangat efektif untuk menyampaikan informasi kepada target audience yaitu wisatawan. Sedangkan untuk media pendukung, media publikasi akan dirancang berupa $T$-shirt, stiker, spanduk, pin dan dll.

Berikut adalah perincian tentang media yang akan dipergunakan dalam perancangan pengembangan wilayah kampung Madras ini:

\section{a. Media Utama}

Media desain utama yang akan digunakan adalah Sign System, Sign System adalah petunjuk informasi bagi wisatawan. Untuk perancangan pengembangan wilayah Kampung Madras ini Sign System-nya akan di kelompokkan menjadi Welcome Sign (orientation \& information), Identification Sign, Direction Sign way finding.

\section{b. Media Pendukung}


Selain media utama, dalam perancangan juga di ikut sertakan media pendukung, tujuannya adalah sebagai sarana untuk mendukung media utama dalam mempromosikan kampung Madras di kota Medan. Di antaranya adalah T-Shirt, brosur dan lain-lain, selain dari itu dengan adanya media pendukung akan bermanfaat untuk mendukung terciptanya pengembangan wilayah ini.

\section{I.2. VISUALISASI}

a. Typografi

Tabel 1. Typografi Sign System Kampung Madras Kota Medan

\begin{tabular}{|c|c|c|}
\hline HEADLINE & JENIS HURUF & STATUS \\
\hline KAMPUNG MADRAS & Arial & $x$ \\
\hline Kampung maøras & Rage Italic & $\mathrm{X}$ \\
\hline KAMPUng MADRAS & Brush Script Std & $x$ \\
\hline kaलpung लadraः⿱ & Samarkan & $\checkmark$ \\
\hline ז̈A MPUNG MaDRAS & Script MT Bold & $\mathrm{x}$ \\
\hline
\end{tabular}

\section{b. Desain Sign System}

Bentuk gopuram yaitu menara bertingkat dari kuil Shri Mariamman di Kampung Madras di jadikan sebagai bentuk template dari semua sign karena bentuk ini merupakan sebuah ciri bangunan khas utama yang ada di Kampung Madras. Diharapkan melalui perancangan sign system pengunjung yang datang ke Kampung Madras dapat mengetahui informasi mengenai keberadaan Lokasi, petunjuk arah dari objek wisata yang ada di Wilayah Kampung Madras. 


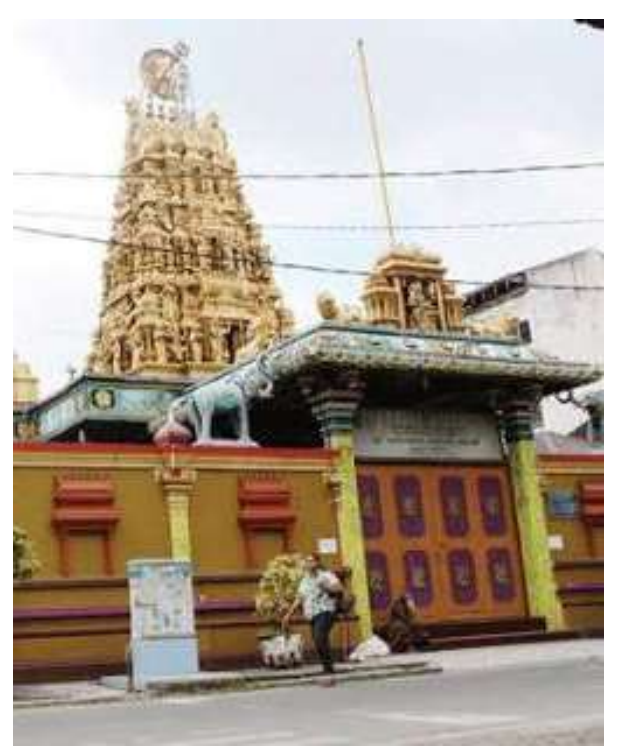

Gambar 5. Kuil Shri Mariamman (Sumber: Dokumentasi Pribadi, 2016)

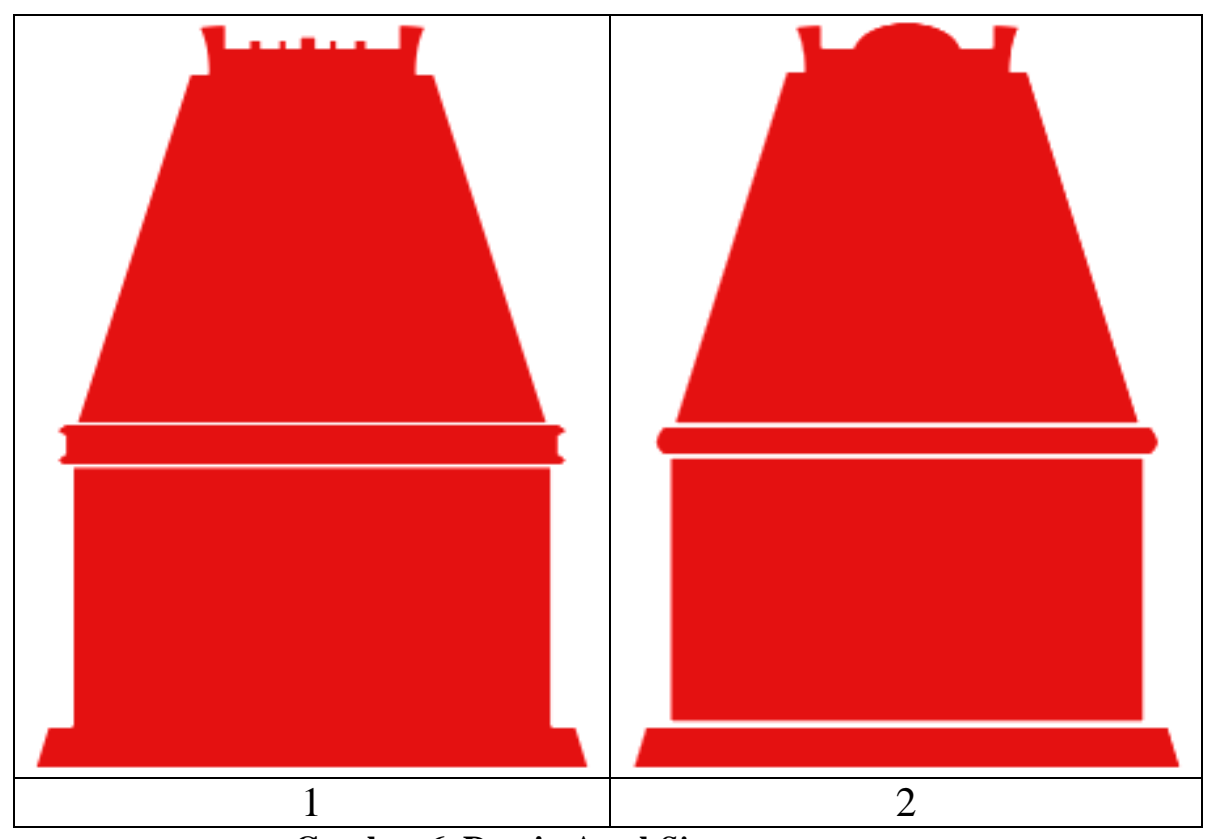

Gambar 6. Desain Awal Sign system

(Sumber: Dokumentasi Pribadi, 2016)

Desain template nomor satu yang di pilih untuk menjadi bentuk dasar desain perancangan pengembangan wilayah Kampung Madras ini 


\section{c. Design Identification Sign, Welcome Sign dan Direction Sign}

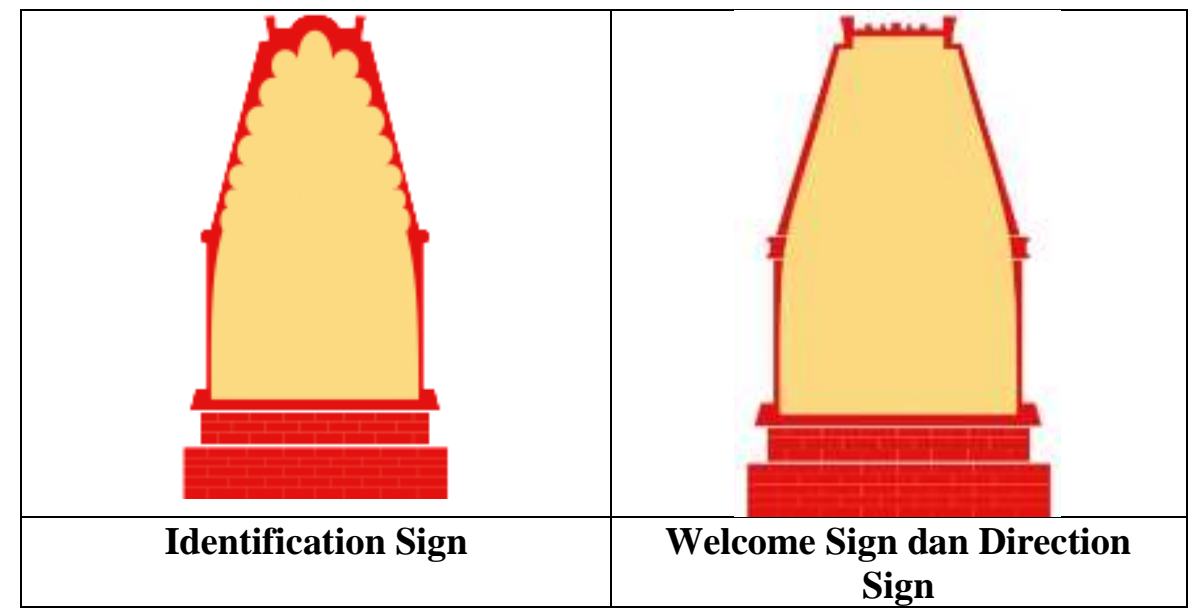

Gambar 7. Design Welcome Sign dan Direction Sign (Sumber: Dokumentasi Pribadi, 2016)

\section{d. Welcome Sign}

Welcome Sign berfungsi sebagai penanda bagi pengunjung ketika masuk ke Wilayah Kampung Madras. Karena sifatnya yang hanya dilihat dalam waktu yang cukup singkat, maka Welcome Sign dibuat dengan ukuran yang besar untuk mempertimbangkan aspek keterbacaan pada Sign. Welcome Sign akan diletakkan di setiap batas wilayah Kampung Madras

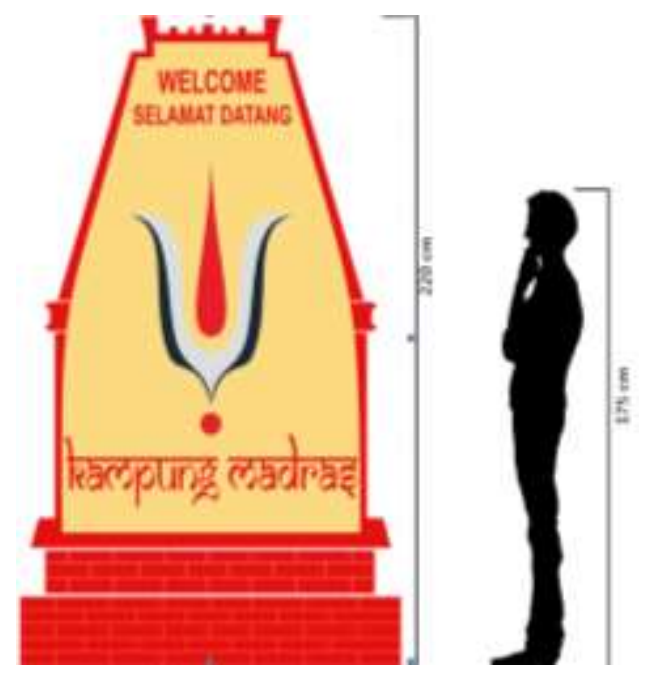

Gambar 8. Welcome Sign Kampung Madras Kota Medan (Sumber: Dokumentasi Pribadi, 2016)

\section{e. Identification Sign}

Identification Sign akan ditempatkan di depan bangunan Objek Wisata. Fungsi dari Identification sign adalah untuk menginformasikan kepada pengunjung nama 
gedung yang sedang dikunjungi. Ukuran yang dipergunakan tidak terlalu besar karena setiap sign dapat diperhatikan dalam waktu yang relatif panjang.

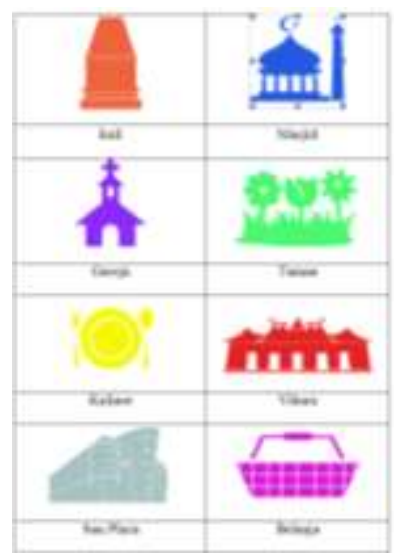

Gambar 9. Indentification Sign Kampung Madras Kota Medan (Sumber: Dokumentasi Pribadi, 2016)
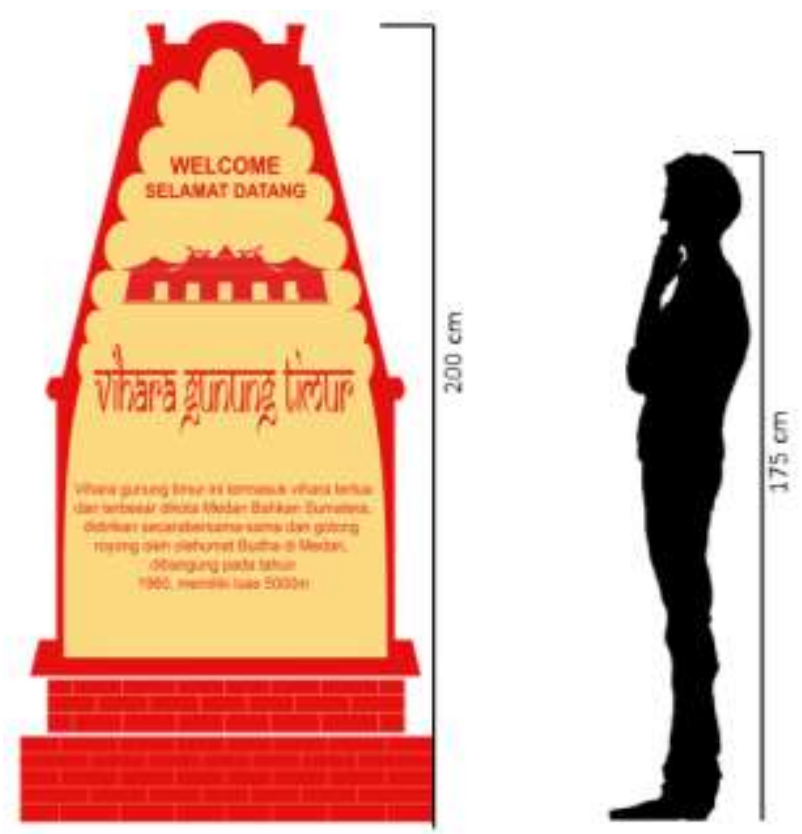

Gambar 10. Desain Indentification Sign Kampung Madras Kota Medan (Sumber: Dokumentasi Pribadi, 2016)

\section{f. Urgent Need Sign}

Sign yang terletak di lingkungan paling luar dan biasanya sangat penting keberadaannya. Fungsinya untuk mengatur arus kendaraan dan pejalan kaki. Meliputi Welcome Sign dan Security Sign. 


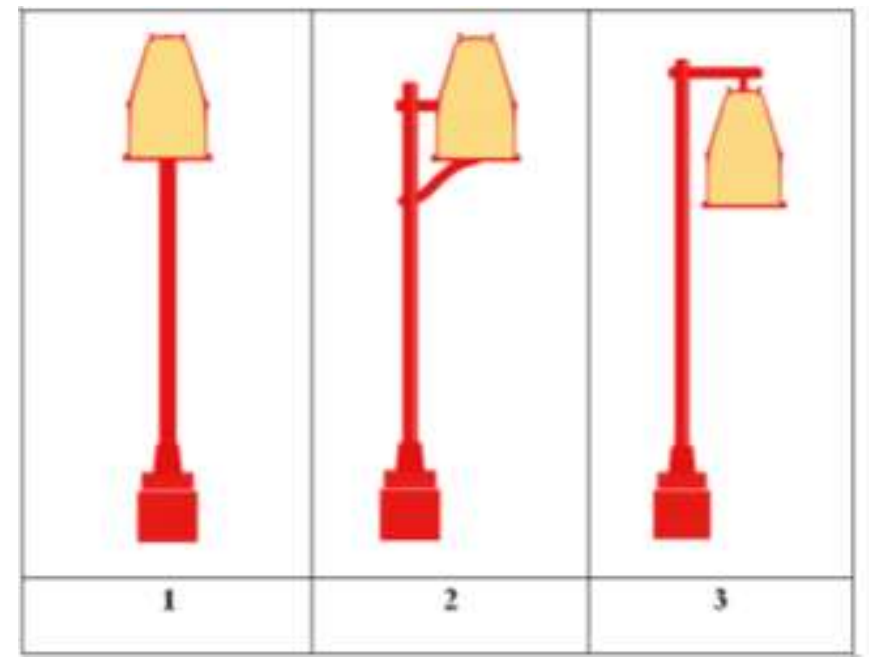

Gambar 11. Alternatif Desain Urgent Need Sign Kampung Madras Kota Medan (Sumber: Dokumentasi Pribadi, 2016)
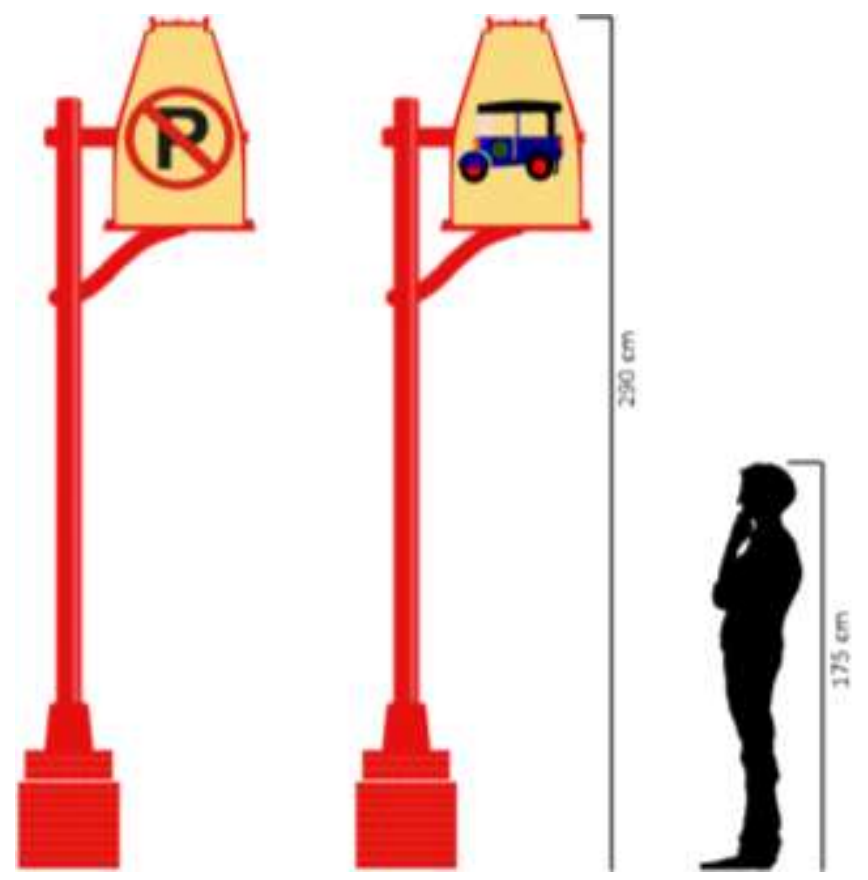

Gambar 12. Alternatif Desain Urgent Need Sign Kampung Madras Kota Medan (Sumber: Dokumentasi Pribadi, 2016)

\section{g. Direction Sign}

Peta Wisata Kampung Madras berisi informasi tentang letak objek wisata yang ada di Kampung Madras. Informasi mengenai objek wisata disampaikan kepada pengunjung dengan pictogram yang telah dirancang sebelumnya. 


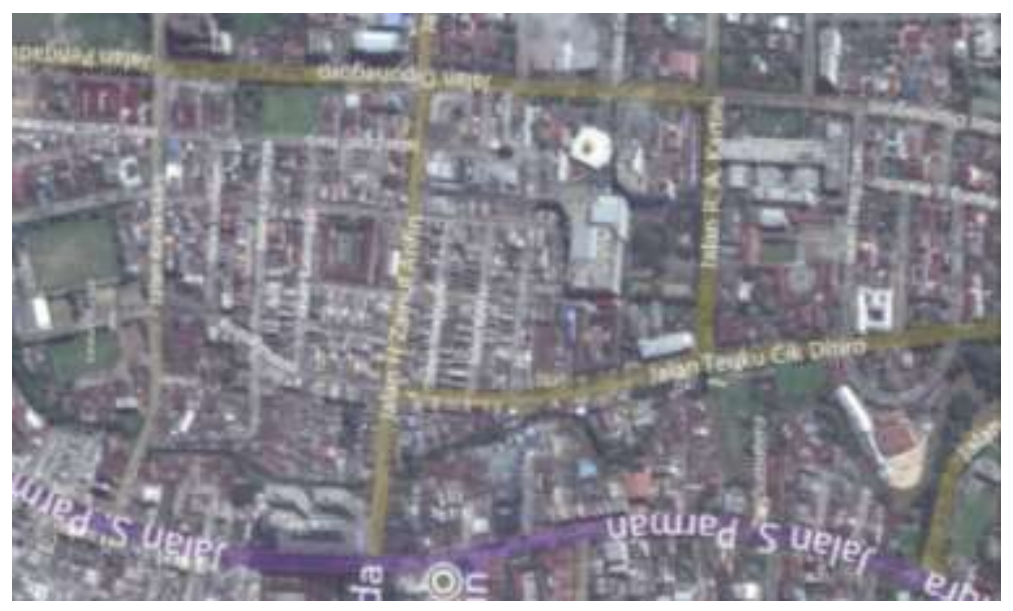

Gambar 13. Peta Kampung Madras Kota Medan (Sumber: GoogleMaps, 2016)

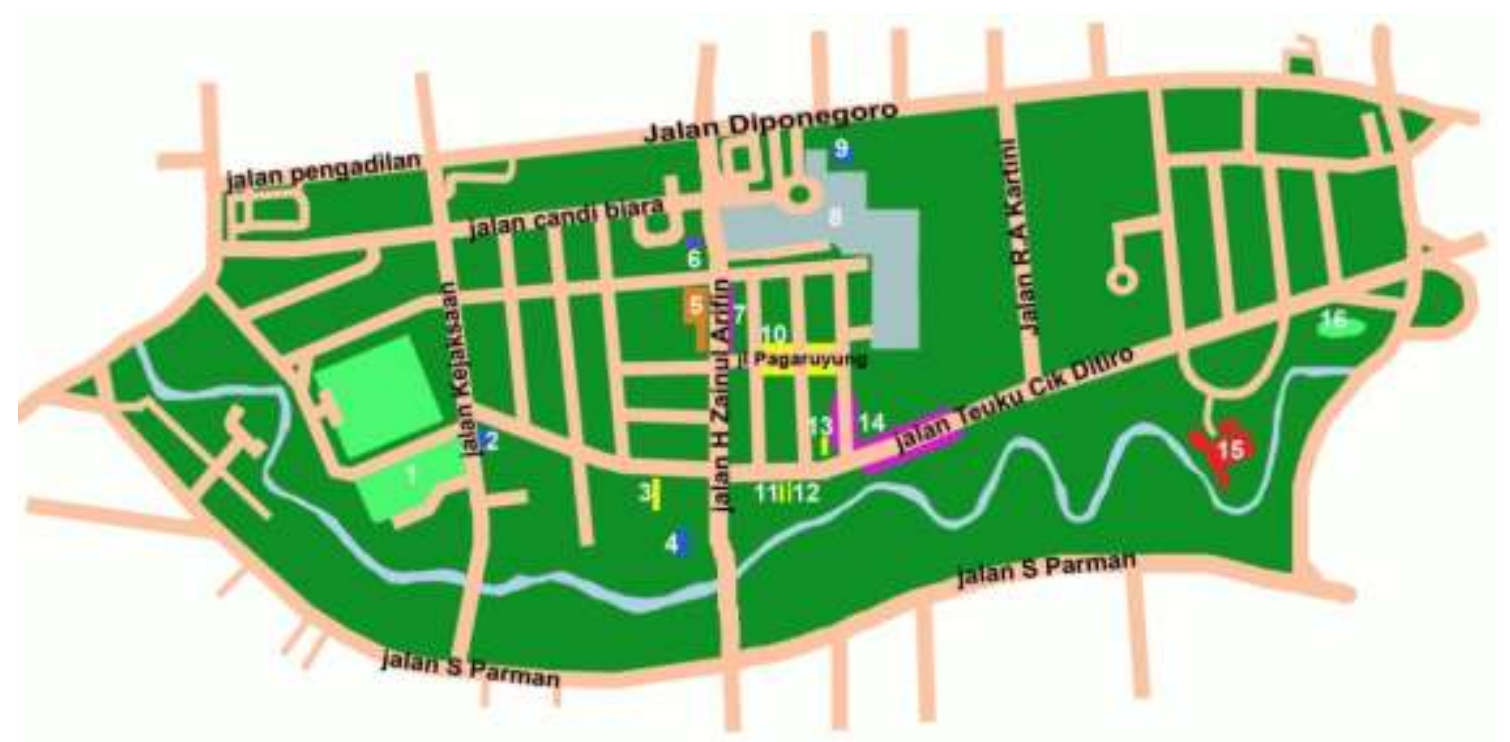

Gambar 14. Desain Map Kampung Madras Kota Medan (Sumber: Dokumentasi Pribadi, 2016) 


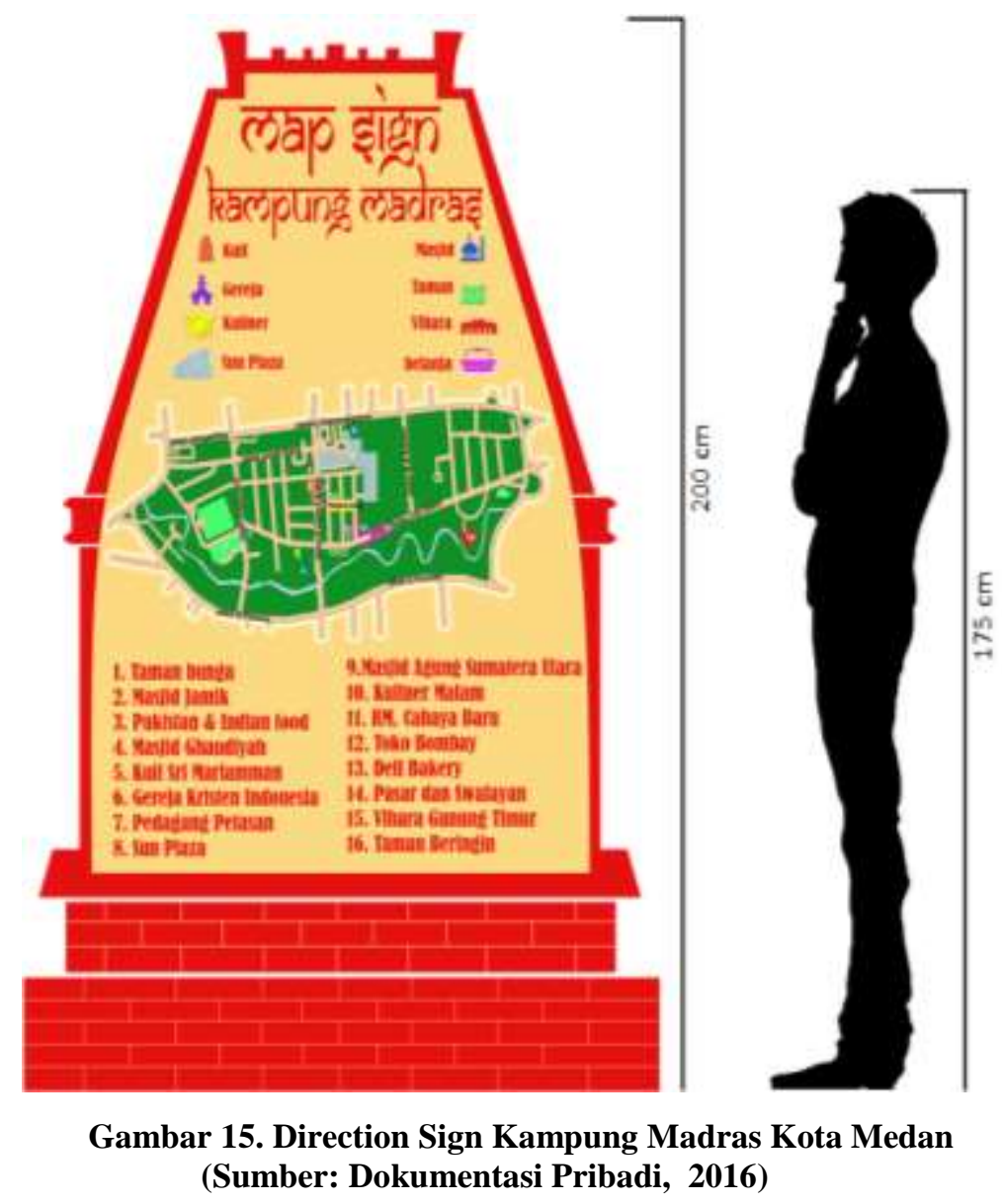

\section{KESIMPULAN}

Kampung Madras merupakan pemukiman yang mayoritas di huni oleh etnis Tamil. Kurangnya sarana petunjuk (signage) di Kampung Madras, seringkali membuat para wisatawan yang ingin berkeliling di kampung Madras kebingungan sehingga menyebabkan aktivitas para pengunjung terganggu. Disini saya membuat alternatif solusi sebagai salah satu cara untuk menyelesaikan permasalahan tersebut yaitu dengan membuat sign system terkonsep sehingga lebih menarik wisatawan untuk melihatnya. Konsep ide perancangan sign system diambil dari bentuk Kuil Shri Mariamman yang menjadi icon kampung Madras tersebut. Semoga dengan adanya Perancangan desain Sign System ini dapat menjadi daya tarik dan membantu para wisatawan untuk berkeliling dengan mudah di sekitaran Kampung Madras.

\section{DAFTAR PUSTAKA}

[1] Adityawan, Johanis. (2015) "Perancangan Sign System Untuk Pasar Rasamala Semarang”. Fakultas Ilmu komputer. Universitas Dian Nuswantoro. Semarang. 
[2] Frutiger, A. (1998). Sign and symbols: Their design and meaning, New York: Watson-Guptill Publications.

[3] Gibson David. (2009). “The Wayfinding Handbook”. New York: Princeton Architectural Press.

[4] Ipsen, G. (2006). From environment to culture: Aspects of continuity. Sign systems studies journal, vol.34(1), London: Tartu Univerisity Press.

[5]Kartika, Rina. (2010). “Konsep Visual Sistem Sarana Isyarat Penunjuk (Sign System) Di Kampus Syahdan Binus University". Jurnal Humaniora Vol.1 No.2. Fakultas Komunikasi Dan Multimedia. Bina Nusantara University. Jakarta Barat.

[6] Nöth, W. (2003). Semiotic foundations of the study of pictures, Sign systems studies journal, vol.31(2), London: Tartu Univerisity Press.

[7] Rustan, Surianto. (2009). “Mendesain logo”. Jakarta: PT Gramedia Pustaka Utama

[8] Sachari, Agus. (2005). "Pengantar Metode Penelitian Budaya Rupa (Desain, Arsitektur, Seni Rupa, dan Kriya)”, Jakarta : Erlangga.

[9] Sinaga, Siska Dorauli tianur. (2016). "Sejarah Kampung Madras Di Kelurahan Madras Hulu Kota Medan”. Fakultas Sosial. Universitas Negeri Medan. Medan

[10] Sularko, Herdi, Prawata, V., \& Widranata, M. 2008. How Do The Think?. Jakarta: Mosher Publishing.

[11] Supriyono, Rakhmat. (2010). "Desain Komunikasi Visual teori dan Aplikasi”.'Yogyakarta: Andi. 